TP Periodica Polytechnica

Transportation Engineering

43(1), pp. 1-8, 2015

DOI: 10.3311/PPtr. 7255

Creative Commons Attribution (i)

RESEARCH ARTICLE

\section{Thermodynamical Examination of the Oily Disc Brake of an Agricultural Motor Vehicle}

\author{
Melinda MENYHÁRTNÉ BARACSKAl ${ }^{1, \text { * }}$
}

Received 13 January 2014

\begin{abstract}
The article examines the thermal problems of the brake system of an agricultural motor vehicle. The functioning of the brake can be considered as reliable if the overheating of the equipment is not present.

Considerable amount of heat is released on the brake discs of the vehicle as a consequence of friction.

In the article there is a brief presentation on the construction, the experiments then the temperature of each element of the brake system after braking. The article analyses the heat transfer and cooling relations. The article defines the volume of the heat transfer factors for the cases cooling of both by air then oil. The article defines what part of the generated heat can be removed from the system by air cooling and by oil cooling respectively.

The main objective of the research is to define whether air cooling is sufficient for the reliable functioning of the equipment or oil cooling must be applied as well.
\end{abstract}

\section{Keywords}

disc brake, heat removal, cooling oil, thermal conduction, heat transfer

\section{Thermal flows taking place during braking}

The examined disc brake system can be found in the wheel hub.

When the vehicle is advancing, the brake system is open and the discs do not contact each other.

The brake house is filled with brake oil up to $19 \mathrm{~mm}$ above the middle of the axis. Therefore, there is no braking until there are heat transfer flows between the elements of the system contacting oil and the brake dressing.

Upon braking, the kinetic energy of the motor vehicle is transformed into friction work while heat is generated. When the hydraulics press the turning discs the oil flowing freely between the discs leaves. During the experiments braking takes place within $2 \mathrm{sec}$. During this braking at maximal intensity heat conduction flows take place between parts contacting each other.

Further, the heat transfer flows can be neglected during the period of braking because braking time is much shorter than the time necessary for heat transfer flows to occur.

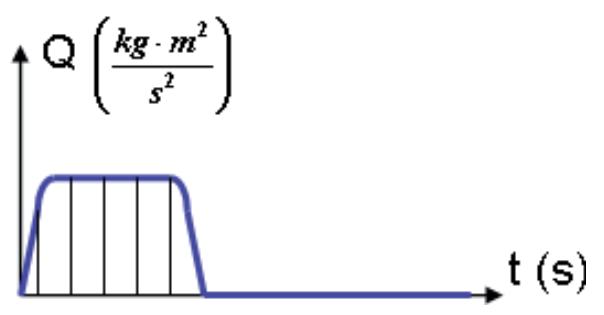

Fig. 1 Thermal load generated during braking time

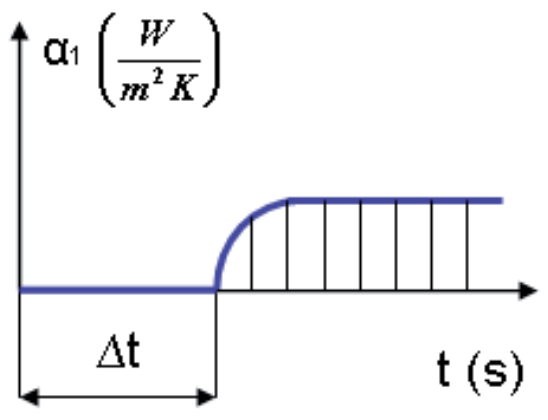

Fig. 2 Heat transfer flows generated after braking
${ }^{1}$ Department of Mechatronics and Machine Design, Szent István University

* Corresponding author, e-mail: baramel@sze.hu 
where:

Q- thermal load

$\alpha_{1}$ - coefficient of heat transfer

$\Delta$ t-idle time

When braking is finished the brake discs open again and brake dressing flows. The brake dressing takes over most of the generated heat from the equipment, then it is lashed against the wall of the brake house. Therefore it transfers a part of the taken heat to the environment. The water cooled oil cooler carries off the heat from the system which remained there.

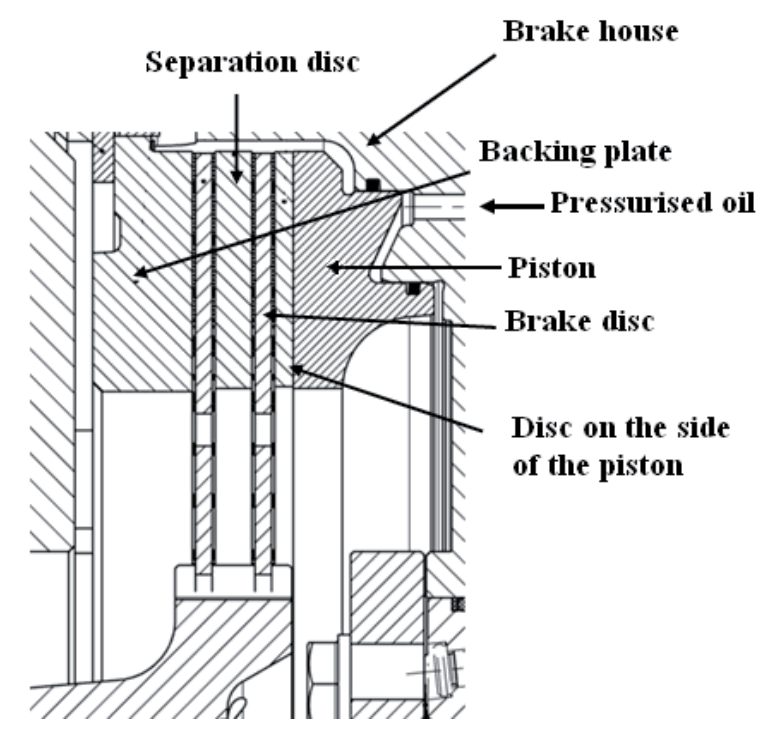

Fig. 3 Main elements of the brake system in the wheel hub.

The two brake discs were made of steel, the backing plate, the separation disc, and the disc on the side of the piston were made of grey cast-iron. On both sides, the brake discs are provided with special paper layers of $1 \mathrm{~mm}$-thickness. The paper layer was made of fibred sheets which is impregnated by resin and additive modifying the friction is added. The main task of the friction layer is to insure the high friction coefficient.

\section{Measurement, measurement results}

The measurement took place with Greening wheel brake system and brake efficiency testing equipment. The equipment can be used for running gears for 2-13 tons of axis load. By this, brake stresses generated in real operation conditions can be produced. Hottinger Spider Mobile 16-channel data acquisition system was used for recording.

As an examination unit, half of a bridge house closed by a blocking disc, and the wheel hub with bearing on it are mounted on the equipment. The half bridge house can be found in the stator part of the equipment.

The external air cooling, or the cooling effect of the ,running wind" is ensured by air flown $0,4 \times 0,6$ by a fan in the pipe system with a cross section of one metre.

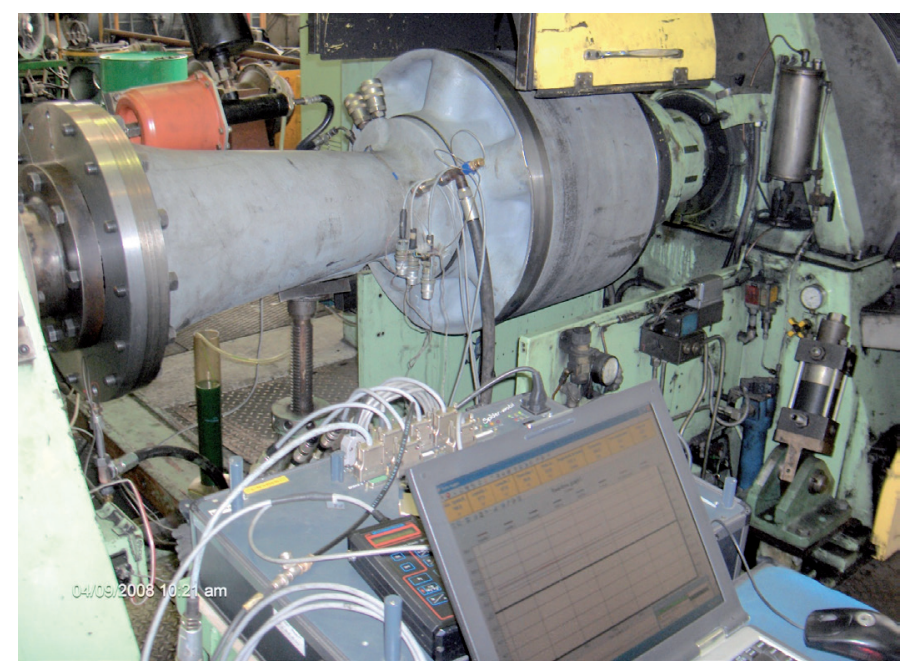

Fig. 4 Bridge house prepared for measurement

During the examination the temperature was measured on the separation disc. The width of the separation disc is $12 \mathrm{~mm}$. Two heat sensors were placed into a bore of $50 \mathrm{~mm}$ depth and $3 \mathrm{~mm}$ diameter.

The first heat sensor is built into the middle of the separation disc that is to say $6 \mathrm{~mm}$ from its edge and the other separation disc is built to a distance of $3 \mathrm{~mm}$ from the edge of the disc.

\section{Temperature form of the disc brake}

During braking, when the generated heat is transferred, the density of heat flux can be written as follows (Benedek et al., 1976):

$$
\begin{gathered}
\dot{q}=\frac{\lambda}{\delta}\left(t_{1}-t_{2}\right) \quad\left(W / m^{2}\right) \\
R_{\text {ell }}=\frac{\delta}{\lambda}
\end{gathered}
$$

where:

$\dot{q}$ - density of heat flux $\mathrm{W} / \mathrm{m}^{2}$

$\lambda$ - coefficient of thermal conductivity $\mathrm{W} / \mathrm{mK}$

$\delta$ - wall thickness $\mathrm{m}$

$\mathrm{t}_{1 ;} \mathrm{t}_{2}$ - temperature values of the elements participating in thermal conduction $\mathrm{K}$

$\mathrm{R}_{\text {ell }}$ - resultant resistance $\mathrm{m}^{2} \mathrm{~K} / \mathrm{W}$

$\lambda_{\mathrm{a}}=43 \mathrm{~W} / \mathrm{mK}$

$\lambda_{\mathrm{sz}}=50 \mathrm{~W} / \mathrm{mK}$

$\lambda_{\mathrm{s}}=0,3 \mathrm{~W} / \mathrm{mK}$

where:

$\lambda_{\mathrm{sz}}$ - coefficient of thermal conductivity of the grey cast-iron $\lambda_{\mathrm{sz}}$ - coefficient of thermal conductivity of the steel

$\lambda_{\mathrm{s}}$ - coefficient of thermal conductivity of the friction layer 
The resultant resistance can be written as a sum of part resistances:

$$
\begin{gathered}
\mathrm{R}_{\text {ell }}=\mathrm{R}_{\text {elvt }}+\mathrm{R}_{1 \mathrm{sr}}+\mathrm{R}_{\mathrm{ft}}+\mathrm{R}_{2 \mathrm{sr}}+\mathrm{R}_{\mathrm{tt}} \\
\mathrm{R}_{\mathrm{ell}}=7,5427 \mathrm{~m}^{2} \mathrm{~K} / \mathrm{W}
\end{gathered}
$$

By reorganising the above equation and by knowing that the temperature of the separation disc learnt from the measurements is $t_{\text {elvt }}=298^{\circ} \mathrm{C}$, the value of heat flow density can be given:

$$
\dot{q}=28902,227 \approx 29 \cdot 10^{3} \frac{\mathrm{W}}{\mathrm{m}^{2}}
$$

Then by defining each wall temperature from step to step:

$$
\begin{gathered}
t_{e l v t-s}=t_{e l v t}-\dot{q} \cdot R_{e l v t}=294,521 C^{\circ} \\
t_{s-f t}=t_{e l v t-s}-\dot{q} \cdot R_{s}=197,854 C^{\circ} \\
t_{f t-s}=t_{s-f t}-\dot{q} \cdot R_{f t}=194,483 C^{\circ} \\
t_{s-t t b}=t_{s-d o t}=t_{f t-s}-\dot{q} \cdot R_{s}=97,817 C^{\circ} \\
t_{t t k}=t_{s-t t b}-\dot{q} \cdot R_{t t}=79,262 \approx 80 C^{\circ} \\
t_{d o t-d}=t_{s-d o t}-\dot{q} \cdot R_{d o t}=94,338 C^{\circ} \\
Q=\dot{q} \cdot A \cdot \tau=5254,8 \mathrm{~W}
\end{gathered}
$$

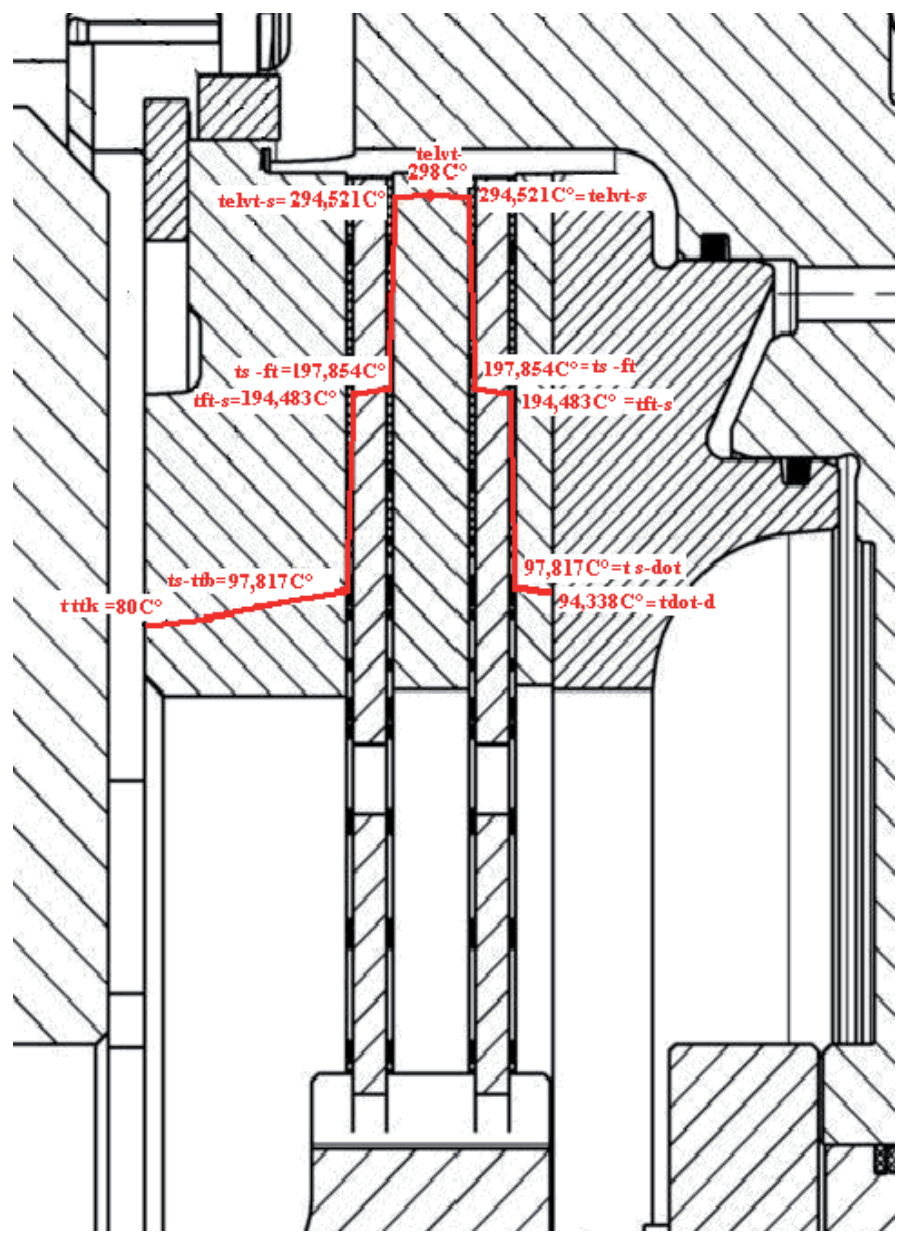

Fig. 5 Temperature distribution

Basic heat equation of Newton on the heat transfer (Janna, 2000)

$$
Q=\alpha \cdot A \cdot t \cdot\left(t_{f}-t_{k}\right)
$$

where:

$\mathrm{Q}$ - heat transfer during convection $(\mathrm{J})$

$\alpha$ - coefficient of heat transfer $\left(\mathrm{W} / \mathrm{m}^{2} \mathrm{~K}\right)$

$\mathrm{t}$ - time of of heat transfer (s)

$t_{f}$ - temperature of the of heat transferring surface $\left(\mathrm{C}^{\circ}\right)$

$t_{k}$ - temperature of the of heat heat-consuming medium $\left(\mathrm{C}^{\circ}\right)$

For defining the heat quantity transferred from the wall of the wheel hub by the air to the external environment, and for defining the heat quantity dissipated by the brake dressing.

The coefficient of heat transfer is not typical to a material but its value depends on several factors.

$$
-\left.\lambda \frac{\partial t}{\partial n}\right|_{f}=\alpha \cdot\left(v_{o}, v, \rho_{m}, \lambda, c_{p}, l, \varphi, T, \ldots\right) \cdot\left(t_{f}-t_{k}\right)
$$

where:

$\alpha$ - coefficient of heat transfer $\left(\mathrm{W} / \mathrm{m}^{2} \mathrm{~K}\right)$

$v_{0}$ - specific volume at normal energy level $\left(\mathrm{m}^{3} / \mathrm{kg}\right)$ 
$v$ - kinematic viscosity modulus $\left(\mathrm{m}^{2} / \mathrm{sec}\right)$

$\rho_{\mathrm{m}}-$ density of mass $\left(\mathrm{kg} / \mathrm{m}^{3}\right)$

$\lambda$ - coefficient of thermal conductivity $(\mathrm{W} / \mathrm{mK})$

$\varphi$ - electrostatic potential (V)

$\mathrm{T}$ - temperature $(\mathrm{K})$

1 - length $(\mathrm{m})$

$\mathrm{c}_{\mathrm{p}}$. - specific heat capacity taken on constant pressure $(\mathrm{kJ} / \mathrm{kgK})$

The temperature on the surface of solid state and the heat flow density on the surface is generated as a result of the interaction with the flowing medium.

Its definition cannot be expected by numeric methods. A flow process can be described by the differential equation of NavierStokes in general but the equation cannot be integrated because the number of uknowns is bigger than the number of equations.

Therefore, the value of the coefficient of heat transfer can be given based on experimental figures and measurement. For writing the heat transfer problems accurately an equation system (IMRE, 1983) should be given, in which the equation written by Navier-Stokes-, Reynolds-, and Fourier-Kirchoff can be found as well.

Nusselt deduced the principles relating to the coefficient heat transfer from the equation of Navier - Stokes by using the similarity principle. Nusselt extended the similarity principle from the pure geometric area to the area of thermodynamics as well. In thermodynamical sense two flow processes are similar if at all the points in the ,appropriate condition" the relationship between the status marker and the material constant is constant. (Faltin, 1970)

\section{Definition of the coefficient of heat transfer of the external transmitting medium}

When giving the external coefficient of heat transfer the flow outside the brake drum should be considered. By simplification, the brake drum can be examined as a cylinder. In this case two different external coefficients of heat transfer should be defined. One coefficient is the value typical to the flow perpendicular to the drum, marked hereinafter by $\alpha_{1}$ while the other one is the coefficient of heat transfer identical with the running direction of the wheel hub relating to its conical side, marked by $\alpha_{2}$.

\subsection{Definition of the coefficient of heat transfer} of the external air flow arriving to the brake drum perpendicularly

$$
\operatorname{Re}=\frac{v \cdot d}{v}
$$

Where the size typical to the flow is the diameter d in Reynolds' criterion.

The coefficient of heat transfer can be given with the Nunumber:

$$
\alpha_{1}=\frac{N u \cdot \lambda}{d}
$$

where:

$\mathrm{d}$ - diameter of the wheel hub $0,62 \mathrm{~m}$

$v$ - kinematic viscosity modulus related to the temperature of

a $20 \mathrm{C}^{\circ}$-environment $15,7 \cdot 10^{-6} \mathrm{~m}^{2} / \mathrm{sec}$

$\lambda$ - coefficient of thermal conductivity $0,025 \mathrm{~W} / \mathrm{mK}$

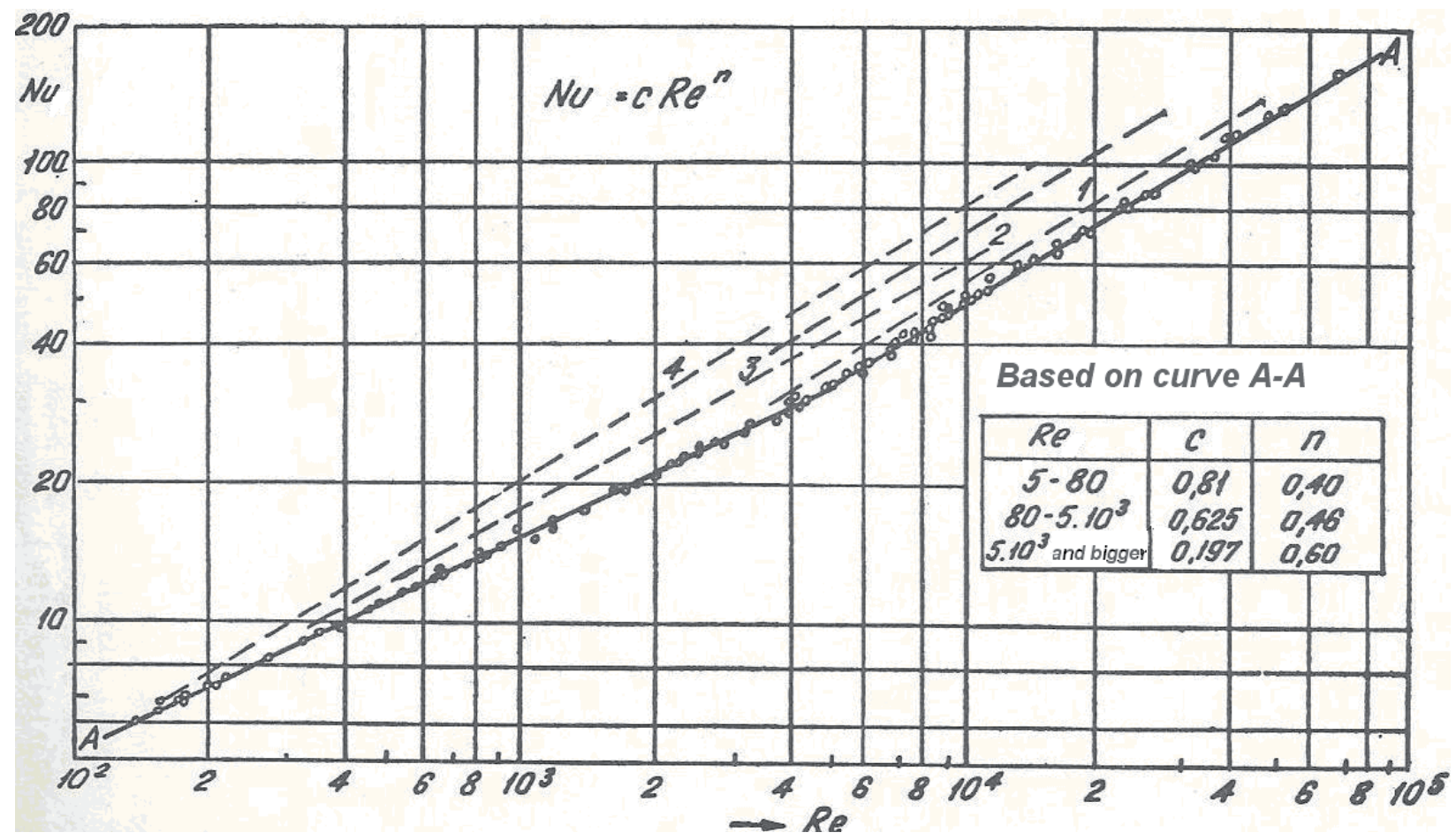

Fig. 6 Heat transfer of the cylinder at perpendicular air flow (Mihejev, 1990) 
Value of Reynolds' number comes to 438344.

$$
N u=c \cdot \operatorname{Re}^{n}
$$

The values of $\mathrm{c}$ and $\mathrm{n}$ constants can be read from Table 16 (Mihejev, 1990) and from Fig. 7 as well:

$\mathrm{n}$ - tangent of the intersection angle of the curve where the flow becomes turbulent.

Based on the diagram (Mihejev, 1990) showing the relationship between the $\mathrm{Re}$ - and Nu-numbers the function can be regarded as linear therefore the Nu-number belonging to the wheel hub of diameter $0,62 \mathrm{~m}$ can be given. Hereinafter it is marked by $\mathrm{Nu}_{62}$.

By supplementation then extrapolation, value of the $\mathrm{Nu}-$ number $N u_{62}=952$.

The value of $\alpha_{62}$ coefficient of heat transfer is $\alpha_{1}=38,40 \frac{J}{m^{2} s K}$

By examining the following criterion equation (Pattantyús, 1961):

$$
N u=c \cdot \operatorname{Re}^{n} \cdot k
$$

Where the values of $\mathrm{c}$ and $\mathrm{n}$ can be given of the table 51,2 and the value of $\mathrm{k}$ can be given of table 51,3 (Pattantyús, 1961):

The Nu-number

$\mathrm{Nu}_{62}=1066$. The value of coefficient of heat transfer from equation (10)

$\alpha_{2}=43,00 \frac{J}{m^{2} s K}$

The following criterion equation (Mihejev, 1990) can be written:

$$
N u=c \cdot \operatorname{Re}^{n} \cdot \operatorname{Pr} k^{0.38} \cdot\left(\frac{P_{r k}}{P_{r f}}\right)^{0,25} \cdot \varepsilon_{\varphi}
$$

where:

$\mathrm{P}_{\mathrm{rk}}$ - Prandt-number, at a long distance from the wall (by taking $20 \mathrm{C}^{\circ}$ as temperature of the environment)

$\mathrm{P}_{\mathrm{rf}}$ - Prandt-number directly next to the wall (the temperature defined as $60 \mathrm{C}^{\circ}$ )

$\varepsilon_{\varphi}-$ correction factor depending on the angle of attack $\varphi$

By presuming that the air arrives to the cylinder at angle of attack $\varphi=90^{\circ}$ the value of $\varepsilon \varphi$ is 1 .

The values of $\mathrm{n}$ and $\mathrm{c}$ can be read from Table 17 (Mihejev, 1990) and from Fig. 7 as well:

$\mathrm{n}=0,61$
$\mathrm{c}=0,26$

$$
P_{r k}=\frac{v_{1} \cdot \rho_{k 1} c_{p 1}}{\lambda_{1}}=0,7368
$$

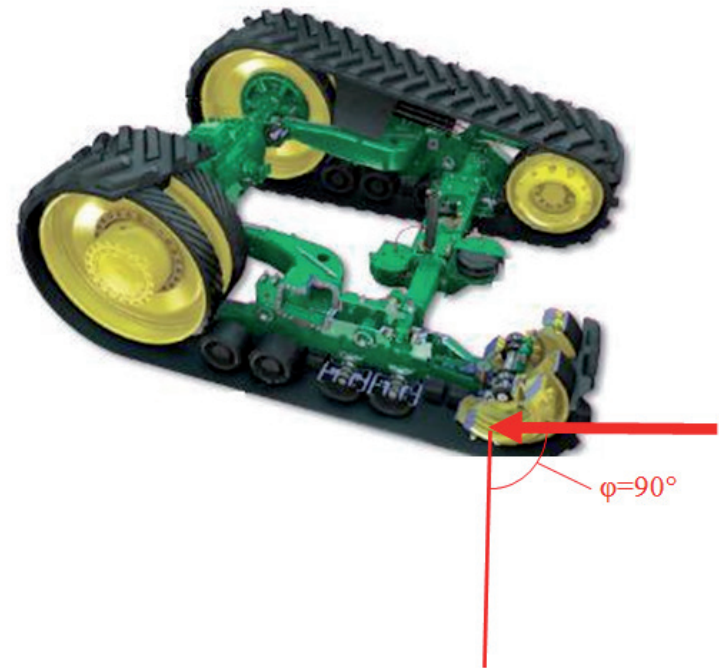

Fig. 7 The air flow arriving to the wheel hub depending of the angle of attack $\varphi$

\begin{tabular}{|c|c|c|}
\hline Temperature & $t_{1}=20 C^{\circ}$ & $t_{2}=60 \mathrm{C}^{\circ}$ \\
\hline Kinematic viscosity & $v_{1}=15,7 \cdot 10^{-6} \mathrm{~m}^{2} / \mathrm{s}$ & $v_{2}=19,4 \cdot 10^{-6} \mathrm{~m}^{2} / \mathrm{s}$ \\
\hline Density & $\rho_{1}=1,164 \mathrm{~kg} / \mathrm{m}^{3}$ & $\rho_{2}=1,025 \mathrm{~kg} / \mathrm{m}^{3}$ \\
\hline $\begin{array}{c}\text { Isobar coefficient of } \\
\text { specific heat }\end{array}$ & $\mathrm{c}_{\mathrm{p} 1}=1,012 \mathrm{~kJ} / \mathrm{kgK}$ & $\mathrm{c}_{\mathrm{p} 2}=1,017 \mathrm{~kJ} / \mathrm{kgK}$ \\
\hline $\begin{array}{l}\text { Coefficient of thermal } \\
\text { conductivity }\end{array}$ & $\lambda_{1}=0,0251 \mathrm{~W} / \mathrm{mK}$ & $\lambda_{2}=0,0279 \mathrm{~W} / \mathrm{mK}$ \\
\hline
\end{tabular}

$$
P_{r f}=\frac{v_{2} \cdot \rho_{k 2} \cdot c_{p 2}}{\lambda_{2}}=0,7248
$$

Needed figures (Ražnjeviç, 1964):

By substitution into equation (13): $\mathrm{Nu}_{62}=842,153$

$\alpha_{3}=33,96 \frac{J}{m^{2} s K}$

The following equation can be written (Kakaç, 1998):

$$
N u=0,033 \cdot c \cdot \operatorname{Re}^{0,8} \cdot \operatorname{Pr} k^{0,4} \cdot\left(\frac{\operatorname{Pr} k}{\operatorname{Pr} f}\right)^{0,25}
$$

If $\mathrm{Re}$ is between $\mathrm{Re}=2 \cdot 10^{5}-2 \cdot 10^{6}$.

$\mathrm{c}$ is the correction factor relating to the number of pipes

The value of the Nusselt number received in this way $N u_{62}$ $=956$

Value of coefficient of heat transfer $\alpha_{4}=38,57 \frac{\mathrm{J}}{\mathrm{m}^{2} \mathrm{sK}}$

\subsection{Definition of the coefficient of heat transfer $\alpha_{5}$ relating to the plane of the wheel hub}

The side of the wheel hub identical with the running direction is slightly conical. On the section of diameter $0,62 \mathrm{~m}$ a difference of $0,01 \mathrm{~m}$ can be seen compared to the plane surface, 
and this difference is considered negligible hereinafter, the external coefficient of heat transfer can be calculated in relation to the plane surface.

It should be considered that in this case the transmitting medium is air. Further, the value of the external coefficient of heat transfer relating to the plane surface is marked by $\alpha_{2}$.

$$
\operatorname{Re}=\frac{c \cdot L}{v}
$$

Where the typical size $\mathrm{L}$ is $. \mathrm{L}=\mathrm{d} \cdot \pi=1,86 \mathrm{~m} . \mathrm{Re}_{2}=1800745$

The following criterion equation can be used because is between $\mathrm{Re}=2 \cdot 10^{5}-2 \cdot 10^{6}$ (Pattantyús, 1961).

$$
N u=0,033 \cdot c \cdot \operatorname{Re}^{0,8} \cdot \operatorname{Pr} k^{0,4} \cdot\left(\frac{\operatorname{Pr} k}{\operatorname{Pr} f}\right)^{0,25}
$$

After the substitution, the following Nu-number is the result: $\mathrm{Nu}=3261,64$

By writing the identity relating to the coefficient of heat transfer with the Nu-number:

$$
\alpha_{5}=\frac{N_{u} \cdot \lambda}{L}=43,83 \frac{W}{m^{2} K}
$$

Quantity of heat removed by air cooling:

$$
\begin{aligned}
& Q_{h}=\alpha_{1} \cdot A_{h} \cdot\left(t_{\text {fal }}-t_{\text {lev }}\right)=1078,74 \mathrm{~J} \\
& Q_{s}=\alpha_{5} \cdot A_{s} \cdot\left(t_{\text {fal }}-t_{\text {lev }}\right)=405,75 \mathrm{~J}
\end{aligned}
$$

where:

$A_{s}-$ section of the plane surface of the wheel hub

$A_{h}$ - section of the cylindrical shell of the wheel hub

$\mathrm{t}_{\mathrm{fal}}$ - temperature of the wall of the equipment

$\mathrm{t}_{\mathrm{lev}}$ - temperature of the external environment

$\mathrm{Q}_{\mathrm{h}}$ - quantity of heat removed by air cooling via the cylindri-

cal shell of the wheel hub

$\mathrm{Q}_{\mathrm{h}}$ - quantity of heat removed by air cooling via the plane surface of the wheel hub

The totally removed heat quantity during air cooling relating to one wheel:

$$
\mathrm{Q}_{\text {levhût }}=\mathrm{Q}_{\mathrm{h}-}+\left(2 \cdot \mathrm{Q}_{\mathrm{s}}\right)=1890,25 \mathrm{~J}
$$

If it is considered that the wheel hub is rotating, the Nusseltnumber can be calculated by the formula of Gobba and Szaundorsza (Szeleznyeva, 1964):

$$
R_{e}=\frac{u \cdot r}{v}=\omega \cdot \frac{r^{2}}{v}
$$

Re - Reynolds-number

$\mathrm{u}$ - running speed $11,11 \mathrm{~m} / \mathrm{sec}$

$\mathrm{r}$ - radius of the external diameter of the disc $0,31 \mathrm{~m}$

$\omega$ - angular velocity
Because the running speed is low therefore the similarity number of Reynolds is much less than the values of Reynoldsnumbers received based on earlier identities.

In this case: $\mathrm{Re}=219369,42$

Because the value is less than the $\operatorname{Re}<2,4 * 10^{5}$ given by author (Szeleznyeva, 1964) identity relating to laminar flow must be calculated:

$$
N_{u}=0,36 \cdot R_{e}^{0,5}
$$

$$
\mathrm{N}_{\mathrm{u}}=168,61
$$

\section{Definition of the so-called internal coefficient of heat transfer relating to the wheel hub}

The internal coefficient of heat transfer should be defined for the plane of the wheel hub separately.

The heat transfer takes lace at $50 \mathrm{C}^{\circ}$ and at $80 \mathrm{C}$. The medium participating in heat transfer is cooling oil.

The coefficient of heat transfer relating to oil $-\alpha_{o}$

By considering the formula marked by Sadik Kakac- Hongtan Liu (Kakaç, 1998):

$$
N u=0,033 \cdot c \cdot \operatorname{Re}^{0,8} \cdot \operatorname{Pr} k^{0,4} \cdot\left(\frac{\operatorname{Pr} k}{\operatorname{Pr} f}\right)^{0,25}
$$

If the Re-number is again between $2 \cdot 10^{5}-2 \cdot 10^{6}$.

For a diameter of $62 \mathrm{~cm}: \operatorname{Re}_{62}=2169956$

Used figures (Ražnjeviç, 1964):

\begin{tabular}{ccc}
\hline Temperature & $\mathbf{t}_{2}=\mathbf{5 0 ~ \mathbf { C } ^ { \circ }}$ & $\mathbf{t}_{1}=\mathbf{8 0 ~ \mathbf { C } ^ { \circ }}$ \\
\hline Kinematic viscosity & $\mu_{2}=54,917 \cdot 10^{-4} \mathrm{Ns} / \mathrm{m}^{2}$ & $\mu_{1}=28,341 \cdot 10^{-4} \mathrm{Ns} / \mathrm{m}^{2}$ \\
Density, oil & $\rho_{2}=52 \mathrm{~kg} / \mathrm{m}^{3}$ & $\rho_{1}=830 \mathrm{~kg} / \mathrm{m}^{3}$ \\
$\begin{array}{c}\text { Specific heat taken at } \\
\text { constant pressure }\end{array}$ & $\mathrm{c}_{\mathrm{p} 2}=1963,5 \mathrm{~kJ} / \mathrm{kgK}$ & $\mathrm{c}_{\mathrm{p} 1}=2089 \mathrm{~kJ} / \mathrm{kgK}$ \\
$\begin{array}{c}\text { Coefficient of thermal } \\
\text { conductivity }\end{array}$ & $\lambda_{2}=0,1435 \mathrm{~W} / \mathrm{mK}$ & $\lambda_{1}=0,141 \mathrm{~W} / \mathrm{mK}$ \\
\hline
\end{tabular}

$$
\begin{aligned}
& v_{1}=\frac{\mu_{1}}{\rho_{1}}=3,415 \cdot 10^{-6} \frac{\mathrm{Ns} / \mathrm{m}^{2}}{\mathrm{~kg} / \mathrm{m}^{3}} \\
& v_{2}=6,445 \cdot 10^{-6} \frac{\mathrm{Ns} / \mathrm{m}^{2}}{\mathrm{~kg} / \mathrm{m}^{3}}
\end{aligned}
$$

where:

$\mu$ - dynamic kinematic viscosity modulus $\mathrm{Ns} / \mathrm{m}^{2}$

$\rho$ - density $\mathrm{kg} / \mathrm{m}^{3}$

Based on equation (14)

$$
P_{r k}=\frac{v_{1} \cdot \rho_{k 1} \cdot c p_{1}}{\lambda_{1}}=42
$$

By writing the identity (15) :

$$
P_{r f}=\frac{v_{2} \cdot \rho_{k 2} \cdot c p_{2}}{\lambda_{2}}=75,13
$$


By substituting back into equation (24), value of the $\mathrm{Nu}-$ number:

$\mathrm{Nu}_{62}=16970$

The value of coefficient of heat transfer relating to oil calculated with this value:

$$
\alpha_{o 1}=\frac{N u \cdot \lambda}{L}=1277,38 \frac{\mathrm{W}}{\mathrm{m}^{2} \mathrm{~K}}
$$

By examining the following criterion equation (Pattantyús, 1961):

$$
\begin{gathered}
N u=0,0356 \cdot \operatorname{Re}^{0,8} \cdot \operatorname{Pr}^{0,4} \\
\operatorname{Pr}=\frac{P_{e}}{R_{e}}=\frac{\frac{w \cdot L}{a}}{\frac{w \cdot L}{v}}=\frac{v}{a}=\frac{\mu}{\rho \cdot a}=42 \\
a=\frac{\lambda}{c_{p} \cdot \rho}=8,13 \cdot 10^{-8}
\end{gathered}
$$

Thus the Nusselt-number:

$\mathrm{Nu}=21683$

$$
\alpha_{o 2}=\frac{N u \cdot \lambda}{L}=1632,078 \frac{\mathrm{W}}{\mathrm{m}^{2} \mathrm{~K}}
$$

where:

$\mathrm{P}_{\mathrm{e}}-$ Péclet-number

a - coefficient of thermal conduction

$c_{p}$ - the Isobar coefficient of specific heat at $80 \mathrm{C}^{\circ}$ temperature is $\mathrm{kJ} / \mathrm{kgK}$

$\lambda$ - the heat transfer factor of oil at $80 \mathrm{C}^{\circ}$ is $\mathrm{W} / \mathrm{mK}$

$\rho$ - oil density at $80 \mathrm{C}^{\circ}$ is $\mathrm{kg} / \mathrm{m}^{3}$

$\mu$ - value of dynamic kinematic viscosity modulus of the oil at $80 \mathrm{C}^{\circ}$ is $\mathrm{Ns} / \mathrm{m}^{2}$

The following solution considers that the oil is colder near the wall therefore its viscosity is bigger therefore the velocity profile is modified as well. Therefore, the Nu-number will be modified as well.

Based on the following formula the $\mathrm{N}_{\mathrm{u}}$ number (Jászay, 1994) can be given:

$$
N u=0,037 \cdot \operatorname{Re}^{0,8} \cdot \operatorname{Pr}_{k}^{0,43} \cdot\left(\frac{\operatorname{Pr}_{k}}{\operatorname{Pr} f}\right)^{0,25}
$$

$N u=21798$

$$
\alpha_{o 3}=\frac{N u \cdot \lambda}{L}=1640,74 \frac{W}{m^{2} K}
$$

A minimal value for the heat transfer coefficient can be defined because only half of the brake drum is filled with oil. In this case the oil does not wet the whole internal surface therefore the $\mathrm{L}$ specific size should be $\mathrm{L}=0,9 \mathrm{~m}$.
The remaining oil in the brake drum should be taken as more important thus its speed generated in the brake drum should be $\mathrm{c}=2 \mathrm{~m} / \mathrm{sec}$

The other features do not change

By this:

$\operatorname{Re}=\frac{c \cdot L}{\mu} \cdot \rho=\frac{2 \cdot 0,9 \cdot 830 \cdot 10^{4}}{28,341}=527151$ the flow is turbulent

Value of the Pr-number does not change

By considering the following identity (Pattantyús, 1961):

$$
N u=0,0356 \cdot \operatorname{Re}^{0,8} \cdot \operatorname{Pr}^{0,4}
$$

Minimal value of the heat transfer coefficient:

$$
\alpha_{o \min }=\frac{\lambda \cdot N u}{L}=933,63 \frac{\mathrm{W}}{\mathrm{m}^{2} \mathrm{~K}}
$$

\section{Heat removal by oil cooling}

The following examination covers how the quantity of heat, which can be removed in the oil cooler by cooling oil, can be defined. The liquid enters the oil cooler at a volumetric flow of $16 \mathrm{l} / \mathrm{min}$. It is circulated by a pump.

$$
\dot{Q}=m_{o} \cdot c_{o} \cdot\left(t_{1}-t_{2}\right)
$$

where:

$m_{o}$ - the volumetric flow of the oil $0,2213 \mathrm{~kg} / \mathrm{s}$

$\mathrm{c}_{\text {po }}$ - specific heat of oil $2089 \mathrm{~kJ} / \mathrm{kgK}$

$\mathrm{t}_{1}$ - medium to be cooled $80 \mathrm{C}^{\circ}$

$\mathrm{t}_{2}$ - cooled medium $64 \mathrm{C}^{\circ}$

Thus $\dot{Q}=7396,7312 \mathrm{~W}$

\section{Presentation of the results}

The article defines the heat distribution of the brake system of a high-performance prime mover running at a speed of 40 $\mathrm{km} /$ hour then braked to stop within the time of 2 seconds. The article gives the temperature of each element of the system after braking by emphasising some of them. The temperature between the separation plate and the friction layer is $294,52 \mathrm{C}^{\circ}$. The temperature of the contact surface between the friction layer and the brake disc is $197,85 \mathrm{C}^{\circ}$. While the temperature measured on the contact surface between the disc on the piston side and the piston is $94,33 \mathrm{C}^{\circ}$. The study defines the values of the heat transfer coefficients with regards to air outside the brake drum and the cooling oil within the drum by using various criterion equations.

Based on the criterion equations examined by myself the value of heat transfer coefficients relating to the environmental air arriving to the cylindrical brake drum perpendicularly based on various pieces of literature: based on the identity in literature (Mihejev, 1990) $\alpha_{1}=38,4 \mathrm{~J} / \mathrm{m}^{2} \mathrm{sK}$, and literature (Pattantyús, 1961) $\alpha_{2}=43 \mathrm{~J} / \mathrm{m}^{2} \mathrm{sK}$, by using the criterion equation of literature (Kakaç, 1998) $\alpha_{4}=38,57 \mathrm{~J} / \mathrm{m}^{2} \mathrm{sK}$. 
The difference between each heat transfer coefficient is not important. In such a case (Mihejev, 1990) $\alpha_{3}=33,96 \mathrm{~J} / \mathrm{m}^{2} \mathrm{sK}$, therefore, I consider this value as the expected minimal value of the $\alpha$ heat transfer coefficient of the external air flow arriving to the brake drum perpendicularly while I consider $\alpha_{2}=43$ $\mathrm{J} / \mathrm{m}^{2} \mathrm{sK}$ as the expected maximal value of the external air flow arriving to the brake drum perpendicularly.

The coefficient of heat transfer defined for the plane of the brake drum: (Pattantyús, 1961) $\alpha_{5}=43,83 \mathrm{~J} / \mathrm{m}^{2} \mathrm{sK}$.

The internal coefficient of heat transfer of the wheel hub is evolved in the following way. If the oil does not wet the whole surface the (Pattantyús, 1961) $\alpha_{\text {omin }}=933,63 \mathrm{~W} / \mathrm{m}^{2} \mathrm{~K}$ by using literature (Jászay, 1994) $\alpha_{03}=1640,74 \mathrm{~W} / \mathrm{m}^{2} \mathrm{~K}$. The value of the heat transfer coefficient defined with another identity differs from this maximal value only to a little extent based on which $\alpha_{\mathrm{o} 2}=1632,08 \mathrm{~W} / \mathrm{m}^{2} \mathrm{~K}$ (Pattantyús, 1961).

The article gives the volume of the heat that can be removed both by air cooling and by oil cooling. The quantity of heat that can be removed by air for one wheel is $1891,25 \mathrm{~J}$, and the quantity of heat removed by oil is $7396,73 \mathrm{~J}$.

The definition of heat transfer coefficients and the knowledge of heat that is removed at every second - that is calculated by using the heat transfer coefficients - are important because, following the definition of all the heat generated upon braking, the further objective of the research is to define whether heat removal only with air cooling is sufficient to reliable functioning or oil cooling should be applied as well.

\section{References}

Benedek, Z., Hatházi, D., Kiss, E., Konecsny, F., Pásztor, E., Perjési, I., Sánta, I., Steiger, I. (1976) Müszaki hö és áramlástan II. (Engineering thermodynamics and hydrodynamics II). Tankönyvkiadó Budapest, pp. 158-162. (in Hungarian)

Faltin, H. (1970) Müszaki hötan. (Engineering Thermodynamics). Budapest: Müszaki Könyvkiadó. pp. 290-301. (in Hungarian)

Imre, L. (1983) Höátvitel összetett szerkezetekben. (Heat transmission in composite structures). Budapest: Akadémiai Kiadó. pp. 75-83. (in Hungarian)

Janna, W. S. (2000) Engineering Heat Transfer. CRC Press LLC. pp. 1-26. Jászay, T. (1994) Müszaki hötan, Höközlés. (Engineering Thermodynamics, Addition of Heat). Müegyetemi Kiadó. pp. 276-279. (in Hungarian)

Kakaç, S. et al. (1998) Heat Exchangers: Selection, Rating and Thermal Design. CRC Press LLC. pp. 99-102.

Mihejev, M. A. (1990) A höátadás gyakorlati számításának alapjai. (Bases of calculation of heat transfer in practice). Budapest: Tankönyvkiadó. pp. 95-99. (in Hungarian)

Pásztor, E. (2006) Untersuchung der Wirkung der Kühlung von Gasturbinen - Scheiben (The determination of the optimum cool air mass flow of turbine blades at gas turbine aircrafts). Periodica Polytechnica Transportation Engineering. 34 (1-2). pp. 1-2. (in German)

Pattantyús, Á. G. (1961) Gépész és Villamosmérnökök kézikönyve 2.: Alaptudományok - anyagismeret. (Manual of Mechanical and Electrical Engineers. Volume 2). Budapest: Müszaki Könyvkiadó. pp. $1197-$ 1201. (in Hungarian)

Ražnjeviç, K. (1964) Hőtechnikai táblázatok. (Heat engineering charts). Budapest: Müszaki Könyvkiadó. pp. 35-106. (in Hungarian)

Szeleznyeva, K. P. (1964) Teplovoe szosztojanie rotorov i cilindrov parovih $i$ gazaovih turbin (Thermal condition of rotors and housings of steam and gas turbines). Moszkva: „Machine construction” Publishing House. pp. 92-93. (in Russian) 